Background Adolescents often lack basic reproductive health $\mathrm{RH}$ information, knowledge, and access to health services for RH. Many have less than favourable attitudes and do not feel comfortable to discuss RH with parents or other key adults.

Objectives To assess RH knowledge, attitude and provider preference among adolescents of age 15 to 19 years.

Methods A community-based cross-sectional study was conducted in Tirana Town, capital city of Albania from October 2012 to January 2013. A structured questionnaire was utilised to collect data from the sampled population.

Adolescents aged between 15 to 19 years old were interviewed about their knowledge and attitudes regarding health services for $\mathrm{RH}$. The data were entered into two different computers using SPSS for windows version 17.00. Descriptive analyses using t-test were employed to depict results.

Results The majority of adolescents knew major health services for $\mathrm{RH}$ and the main health service providers of $\mathrm{RH}$.

The major sources of information for $\mathrm{RH}$ were internet radio $92 \%$ and television and radio for $61 \%$ school teachers for $35.9 \%$ and parents $28 \%$ of respondents.

Conclusion The level of knowledge and attitude about health services for $\mathrm{RH}$, source of information for these services and service provider centres is encouraging. However, the role of health professionals and families as the source of information for the adolescents seems to be low. This should be improved using a more integrated all stakeholders particularly adolescents' families and health professionals who have a vital role to ensure adequate knowledge and favourable attitudes for utilisation of the RH in the locality.

\section{P4.096 SEXUAL NETWORK AND PRACTISE OF FEMALE SEX WORKERS IN SIKKIM}

doi:10.1136/sextrans-2013-051184.0994

S Chowdhury, N Panda, M Kundu, R Basu, R Sonkar, S Das Konar, A RoyChoudhury. CINI, Kolkata, India

The problem 'Sikkim is an orthodox state in India. It has a traditional society which believes that polygamy does not exist. There was no authentic study to validate the statement. According to the estimate of 2007, prevalence rate of HIV was 0.6.Though Sikkim SACS is running Targeted Intervention programme, the target population is a hidden one and no penetration is happening by TI' (Valla A, 2006).

A study was conducted on socio sexual network and practise of Female Sex Workers (FSWs) in collaboration with Sikkim SACS in the month of Nov, 2012.

Methodology Sample size was 70 selected through Stratified random sampling (10\% of the total population registered under NGO programmes of Sikkim SACS)

Result and discussion $70 \%$ of respondent is engaged in sex work along with other profession while $30 \%$ is dependent solely in sex work profession. $88 \%$ of respondent is coming to sex work profession for economic reason. Among this $88 \%, 65 \%$ is working for less than 1 year. $70 \%$ of respondent work more than 20 days a month having an average of 30 partners. $80 \%$ of respondent are below age 25 yrs who have more than 30 sexual partners -i.e. less age group is more vulnerable. $80 \%$ of the respondent consumed alcohol. Among $70 \%$ of alcohol users, $90 \%$ is not using condom. $10 \%$ of the respondent taking drug through injecting route. $90 \%$ of respondents have heard of HIV while $30 \%$ of them have accessed TI services. $10 \%$ of respondent explained about STI sign \& symptoms whereas the prevalence rate is $70 \%$.

Conclusion The study shows that polygamy exists in the state and an emerging trend of new FSW noticed. Condom use, knowledge of STI and HIV both are low. The national control programme should develop Sikkim specific design to address these issues.

\section{P4.097 IS THE MINIMUM PACKAGE OF PREVENTION INTERVENTION WORKING? OUTCOME OF COMBINED PREVENTION INTERVENTION AMONGST IN - SCHOOL YOUTHS IN KWARA STATE, NORTH CENTRAL, NIGERIA}

doi:10.1136/sextrans-2013-051184.0995

A Omoloja, 10 Omotoso, ${ }^{1} \mathrm{C}$ Nwuba, ${ }^{1} \mathrm{~S}$ Faromoju, ${ }^{2} \mathrm{~N}$ Ndulue, ${ }^{3} \mathrm{~J}$ Alayande. ${ }^{1}$ Management Sciences for Health (MSH), Ilorin, Kwara State, Nigeria, ${ }^{2}$ Management Sciences for Health (MSH), Abuja, Federal Capital Territory, Nigeria, ${ }^{3}$ Government Secondary School, Bode Sa'adu, Kwara State, Nigeria

Background Adolescents are among the vulnerable groups at risk of HIV infection. In Nigeria,the high HIV prevalence and teenage pregnancies amongst in-school youths underscores the need to implement effective interventions that address risky sexual behaviours and ultimately reduces the transmission of HIV. This study examines the outcome of Combined Prevention Interventions (CPI) amongst in-school youths in Kwara state,Nigeria.

Methods The MSH Nigeria USAID funded ProACT project supports the Kwara State Government to implement effective and sustainable HIV prevention intervention that promotes adoption of abstinence amongst in-school youths. At Government Secondary School, Bode Sa'adu, 30 (13Males, 17Females) students were trained as Peer Educators using the Family Life HIV Education (FLHE) training package. Information for planning effective HIV Prevention interventions for the target population was generated through questionnaires administration and Focus Group Discussions. The knowledge and skills acquired by the PEs were cascaded to other students using the Minimum Package of Prevention Intervention (MPPI), which addresses behaviour change through the combination of prevention interventions targeted at individuals and communities. Each PE formed a cohort group of 10-15 peers and conducted activities under the Abstinence and/or Be Faithful prevention strategies to promote adoption of positive sexual and reproductive health (SRH) behaviour among their peers. Outcome of the prevention intervention on teenage pregnancies pre and post interventions were analysed.

Results Prior to this intervention, about 10-15 unintended teenage pregnancies were recorded annually (from 2005-2011) at the school resulting in school dropout, unsafe abortion and death. However,after 20 months of implementation,number of teenage pregnancies reduced from 11cases in April 2011 to zero in December 2012. In addition,students also acquired life building skills that resulted in their overall academic improvement and wellbeing.

Conclusion Effective implementation of the CPI/MPPI that focuses on addressing individual and community behaviour can go a long way in achieving sustainable positive SRH behaviours among in school youths.

\section{P4.098 HIV AND YOUR BODY - A COMMUNITY BASED HEALTH AWARENESS PROGRAMME: ADVANTAGES OF MULTIDIMENSIONAL COMMUNICATION STRATEGIES ON THE EXAMPLE OF AUSTRIA}

doi:10.1136/sextrans-2013-051184.0996

'B Leichsenring, ${ }^{2} \mathrm{~B}$ Dannoritzer, ${ }^{3} \mathrm{H}$ Garcia, ${ }^{4} \mathrm{G}$ Picher, ${ }^{5} \mathrm{~W}$ Stefanek. ${ }^{1}$ Aids Hilfe Wien, Vienna, Austria, ${ }^{2} H I V m o b i l$, Vienna, Austria, ${ }^{3}$ Positiver Dialog, Vienna, Austria, ${ }^{4}$ LMCVienna, Vienna, Austria, ${ }^{5}$ PULSHIV, Vienna, Austria

Background Progression of chronic HIV-infection, management of comorbidities or coinfection with STIs is significantly influenced by individual dealing with health and lifestyle issues. PLHIV therefore have an increased need for information and support regarding personal health.

Methods "HIV and Your Body" is an international informational programme promoting health awareness in PLHIV. Activists of community and topic related NGOs are annually trained during an 